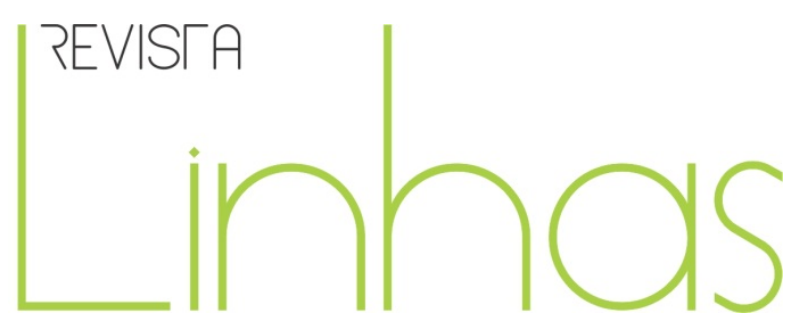

\title{
A herança weberiana n'Os herdeiros: entre o projeto moderno não realizado e a aposta na razão
}

\begin{abstract}
Resumo
O artigo tem por objeto a compreensão do modus operandi da apropriação de conceitos e do método weberiano na obra de Pierre Bourdieu e Jean-Claude Passeron "Os Herdeiros - os estudantes e a cultura". Sustentamos a ideia de que essa apropriação é referenciada em dois vetores: demonstrar o caráter mistificado e mistificador do modo de relação dos estudantes com o sistema de ensino, e como ferramenta que indica um projeto não realizado, que necessitaria ter na razão seu elemento balizador que possa ser levado a efeito. Entendemos que esse movimento resulta em uma aposta política dos autores sobre a configuração que o sistema de ensino deveria ter para cumprir a função social a ele atribuída no projeto moderno, em particular no que tange ao ideal da igualdade e à política francesa de democratização da educação.
\end{abstract}

Palavras-chave: Projeto educacional moderno; Educação superior; Método weberiano.

\author{
Santiago Pich \\ Doutor em Ciências Humanas \\ pela Universidade Federal de \\ Santa Catarina - UFSC - Brasil \\ santiago.pich@yahoo.com.br
}

\footnotetext{
Para citar este artigo:

PICH, Santiago. A herança weberiana n'Os herdeiros: entre o projeto moderno não realizado e a aposta na razão. Revista Linhas. Florianópolis, v. 15, n. 29, p. 251-269, jul./dez. 2014.
}

DOI: $10.5965 / 1984723815292014251$

http://dx.doi.org/10.5965/1984723815292014251 


\title{
The weberian inheritance in The inheritors: between the unrealized modern project and the bet on reason
}

\begin{abstract}
This article aims to understand the modus operandi and the appropriation of concepts and Weberian method within the work "The Heirs - the students and the culture". We hold the view that this appropriation is guided by two vectors: demonstrating the mystified and mystifying character of the mode of relationship of students with the education system, and as a tool that indicates a not accomplished project which should have the rationality as its guideline. We understand that this movement results in a political position of the authors that assume on the configuration that the educational system should have in order to fulfill social functions ascribed to it in the social project of the modernity, in particular with respect to the ideal of equality and the French policy of democratization of education.
\end{abstract}

Keywords: Modern educational project; Higher education; Weberian method. 
O problema da "herança cultural" é central na análise do sistema de ensino realizada por Pierre Bourdieu, tanto individualmente, quanto nas obras produzidas em parceria com Jean-Claude Passeron. No entanto, a elaboração desse problema ganha contornos específicos nos diferentes textos dedicados a essa análise. Em particular na obra "Os Herdeiros - os estudantes e a cultura", marco fundador dos estudos de sociologia da educação bourdieusianos, observamos uma maneira singular no que diz respeito ao modo com o qual os autores se valem dos conceitos e do método de pesquisa weberiano para, em movimento paralelo, apresentar um severo diagnóstico da configuração do sistema de ensino universitário objetivando demonstrar o caráter reprodutor do mesmo com relação às desigualdades sociais (tanto de classe quanto de sexo $\left.{ }^{1}\right)$, assim como para sustentar a tese de que esse estado de coisas poderia ser outro se o projeto moderno, assentado na razão, fosse levado a cabo.

Embora seja largamente conhecida a influência weberiana no pensamento de Pierre Bourdieu, poucos são os trabalhos que se debruçam sobre esse tema, e ainda menores são as análise que focalizam essa relação nos estudos bourdieusianos no campo da educação. Interessa-nos neste trabalho o modus operandi com que Bourdieu e Passeron se valem de conceitos e do método weberiano. Entendemos que o uso do conceito de tipo ideal de ação, concretamente a ação racional com relação a fins e com relação a valores, cujo uso se encontra presente de forma decisiva no terceiro capítulo do livro e na conclusão, é utilizado como uma ferramenta teórica que comporta tanto uma dimensão compreensiva, quanto normativa. Assim, sugerimos que a utilização sui generis desse conceito e do método do qual é uma ferramenta constitutiva, se torna uma baliza a partir da qual se procura desvendar a relação mistificada dos estudantes com a cultura escolar universitária, assim como se erige também como um horizonte normativo para demonstrar como seria (ou deveria ser?) a relação desses atores sociais com a vida

\footnotetext{
${ }^{1}$ Utilizaremos aqui o termo sexo ao invés de gênero para sermos fiéis ao termo utilizado pelos autores na obra aqui discutida. Porém, entendemos que a análise realizada n'Os Herdeiros se aproxima da perspectiva de gênero, uma vez que as identidades masculina e feminina não são tomadas como elementos universais e necessários (em perspectiva essencialista), mas situadas a partir dos condicionantes socioculturais que as definem, em particular a condição de classe.
} 
universitária, caso operassem a partir de uma relação entre meios e fins pautada na ação racional com relação a fins. Não menos importante nesse movimento de construção teórica, é o papel do professor universitário, aquele que, na leitura proposta na obra, não deveria ocupar o lugar de profeta, ou melhor, daquele que "professa" sobre o destino dos eleitos, justificando e legitimando a relação mistificada dos estudantes com a cultura escolar universitária. Devemos apontar, ainda, que essa perspectiva analítica precisa ser situada na esteira do processo de racionalização do mundo da tradição ocidental, o qual também é um princípio teórico-metodológico de origem weberiano.

Essa análise é complementada por uma proposta, baseada na posição dos autores que advogam em favor de uma pedagogia racional que emerge como um horizonte possível para superação de uma modernidade ainda presa nas amarras da tradição e da relação dos sujeitos com a cultura escolar universitária pautada no privilégio dos privilegiados, permitindo abrir uma perspectiva promissora para pensar o sistema de ensino francês como uma instituição social de capital importância para a promoção da igualdade social. Além disso, a orientação racional da ação e a pedagogia racional permitiriam superar a reprodução da lógica da dominação tradicional que se faz presente no sistema de ensino, com destaque para o nível superior, a qual "favorecendo os favorecidos", reforça a transmissão por herança de privilégios culturais e sociais aos "bem nascidos".

No presente trabalho apresentamos, no primeiro momento, os conceitos weberianos e o método weberiano, com ênfase para o conceito de tipo ideal de ação, com relação a fins e a valores, e situamos elementos básicos da teoria da dominação; também descrevemos os contornos do diagnóstico realizado por Weber sobre o predomínio de um determinado tipo de ação racional na modernidade capitalista. $\mathrm{Na}$ sequência, com base nessa referência teórico-metodológica, analisamos o modo de apropriação desses conceitos no livro em estudo. 


\section{Max Weber, a racionalização do mundo e o tipo ideal de ação}

No seu projeto sociológico, Max Weber procurou, em sintonia com o espírito da época, definir a especificidade das ciências sociais (ou do espírito Geisteswissenschaften), dando primazia à ação social. Nesse movimento, ele constrói seu modelo teórico-metodológico tendo como um dos seus principais vetores o "tipo ideal” (WEBER, 1999). Para tanto, Weber identifica que na modernidade emerge como hegemônico um tipo de dominação, o tipo-ideal de dominação burocrática ou racionallegal, contexto no qual o tipo de ação racional com relação a fins (Zweckrational) é central.

Para Weber (1999) é possível constatar a presença ao longo da história de três tipos ideais de dominação: a dominação carismática, a dominação tradicional e a dominação racional-legal ou burocrática. Em particular, nos interessam as duas últimas. A forma ideal-típica de dominação tradicional se encontra em sociedades estamentais em que um grupo ou casta se perpetua no poder por conta de convenções sociais principalmente através da transmissão hereditária da condição estamental - que permitem a reprodução da ordem social de maneira inalterada. Ainda, se caracteriza por ser pessoal (pela forma de transmissão da autoridade), e por ser de caráter ordinário. Por outro lado, a dominação burocrática se pauta na impessoalidade das relações, em um alto grau de racionalização da administração, na especialização dos quadros, na disciplina e em um aparato jurídico-político que ordena e regula as relações sociais. Essa forma idealtípica de dominação é de caráter impessoal e ordinário. Na análise weberiana a dominação racional-legal seria tipicamente moderna e estaria presente nas instituições que emergem nesse período histórico, superando a dominação tradicional. Entendemos, conforme ampliaremos no próximo tópico, que a denúncia realizada por Bourdieu e Passeron também se assenta no argumento de que as instituições que pretensamente deveriam contribuir para a realização da dominação racional-legal tipicamente moderna, neste caso o sistema de ensino, e o sistema de ensino superior em particular, ainda se encontram presas nas amarras da dominação tradicional, privilegiando “Os Herdeiros". 
Na sociologia de Max Weber, o tipo ideal é uma elaboração teórica, construída a partir da relação do pesquisador com a realidade social, que permite definir heuristicamente dimensões específicas dessa realidade, destacando aspectos considerados centrais para a configuração da dinâmica social e para a compreensão das relações sociais, sem nunca ter a pretensão de coincidir com o real. Esse conceito está em consonância com o postulado metodológico de Weber com relação à objetividade nas ciências sociais, o qual sinaliza, por um lado, a impossibilidade de apreender objetivamente a realidade social, assumindo como necessária a implicação do pesquisador com o objeto e com os conceitos produzidos, procedimento que não pode, porém, por outro lado, ser realizado sem manter a pretensão de manter distantes os juízos de fato e os de valor, evitando que os modelos teóricos construídos se tornem balizas normativas para a práxis social. Assim, os tipos ideais são sempre modelos aproximativos, gerais e provisórios, não são falsos ou verdadeiros, mas válidos ou inválidos, isto é, o que importa é o grau de operatividade do tipo ideal em questão. Eles se relacionam com a descrição de um curso de ação orientado a alcançar um único fim, e se vinculam a um percurso normativamente ideal de ação. Contudo, Weber alerta para o fato de que eles nunca se encontram na realidade social em forma "pura", mas sempre em relação com outras formas de orientação da ação. Por consequência, o tipo ideal serve de parâmetro de contrastação com a realidade (aproximação ou afastamento do tipo ideal), e para elaborar hipóteses sobre o caráter da orientação da ação, se racional ou irracional (WEBER, 2003a p. 60-66).

Com relação aos tipos ideais de ação, o sociólogo alemão propõe considerar quatro: a ação tradicional, a ação afetiva, a ação racional referente a valores e a ação racional referente a fins (WEBER, 1999). Cumpre, para os fins deste trabalho, diferenciar os dois tipos de ação racional. A ação racional com relação a valores se pauta pela orientação do agir a partir de uma ordem axiológica definida a partir de crenças religiosas, morais, ou de caráter estético, considerados como um mandamento pelo agente, sem que o fim da ação seja definido em termos instrumentais, mas pela convicção da importância dos valores defendidos para a construção de uma determinada ordem social ou para o grupo social ao qual o agente pertence. Com relação à ação 
racional com relação a fins, Weber (1999) afirma que: "age de maneira racional referente a fins quem orienta sua ação pelos fins, meio e consequências secundárias, ponderando racionalmente tanto os meios em relação às consequências secundárias, assim como os diferentes fins entre si." (p. 16). Assim, quem orienta sua ação desse modo estabelece uma relação de cálculo eficaz entre os meios e os fins que procura alcançar, sendo que os meios escolhidos e as consequências de sua utilização serão passíveis de serem situados no escopo do cálculo realizado. Ainda, esses dois tipos de ação não estão isentos de serem balizadores do comportamento dos agentes, uma que vez que: "A decisão entre fins e consequências concorrentes e incompatíveis, por sua vez, pode ser orientada racionalmente com referência a valores: nesse caso, a ação só é racional com referência a fins no que se refere aos meios." (Ibid., p. 16). Isto é, uma vez definida uma ordem éticonormativa, o cálculo de eficácia entre meios e fins poderia ser subordinado a essa ordem axiológica. Importante é destacar que esses dois tipos de ação se diferenciam dos tipos de ação afetiva e tradicional na medida em que nelas a produção de sentido da ação é consciente e parte do agente.

Esse construto teórico cumpre tanto uma função compreensiva, sendo uma ferramenta que permite situar os elementos que identificam a ação social racional, assim como também pode ser utilizado como baliza para contrastar com ela as ações que não se ajustem a esses critérios. O tipo ideal de ação racional e o modo de operação com ela são fundamentais na estratégia argumentativa do terceiro capítulo e da conclusão d'Os Herdeiros, discussão que abordaremos no próximo tópico.

Retomando a discussão em torno dos conceitos e do método weberiano é relevante destacar que para o sociólogo alemão não é possível descobrir leis imanentes da história, porém, pode-se sim identificar, ex post facto, princípios que orientam o desenvolvimento histórico de uma ordem social. Na análise da tradição ocidental exsurge de forma destacada a racionalização do mundo. A raiz desse fenômeno é de natureza religiosa, estendendo-se no decurso da história para outras esferas da vida social. Enquanto em outros contextos, como na Índia, a racionalização do mundo não se observa, permanecendo como um “jardim encantado” (WEBER, 1982), no ocidente, identificado com a tradição judaico-cristã, se observa crescente racionalização do mundo, 
que alcança sua forma mais elaborada com o puritanismo calvinista, no qual se evidencia de forma clara a retirada dos meios mágicos de salvação e o desenvolvimento da ascese intramundana (WEBER, 1982 e 2004). Nesse contexto, a busca pela salvação se realiza tão somente a partir da ação racional dos sujeitos pautada pelos preceitos ético-normativos que fundam esse movimento religioso.

Embora, Weber evite sempre fazer prognósticos nas análises que realiza a partir do seu modelo teórico, procurando fugir dos julgamentos que comportem juízos axiológicos, reconhece as conquistas do processo de racionalização do mundo. Porém, não realiza uma avaliação ingênua desse processo, mantendo um olhar ambivalente com relação aos possíveis desdobramentos do projeto triunfante no ocidente moderno. Ainda, para o autor, a orientação racional com relação a fins comporta o risco de colonizar a forma do ser humano operar com a razão, limitando a ação racional a um cálculo de eficácia de meios e fins, fins esses definidos pela lógica econômica. $\mathrm{Na}$ análise weberiana da modernidade capitalista, a relação entre meios e fins a partir do cálculo econômico se impõe a todos os seres humanos como um dever do qual nenhum indivíduo está isento. Na obra “A Ética Protestante e o Espírito do Capitalismo", postula que a transferência da ética protestante para o universo do capitalismo moderno se impõe com tal força que, agindo maquinalmente, se torna a única maneira legítima de operar com a razão. (WEBER, 2004). Assim, vemos que o domínio da ação racional com relação a fins que se tornou hegemônico na modernidade está muito longe de promover uma libertação do ser humano das amarras da tradição, mas, pelo contrário, mantém o ser humano em uma condição de heteronomia.

Em decorrência disso, podemos sustentar a ideia de que a lógica tecnocrática que se depreende de tal cenário, se impõe também no âmbito do sistema de ensino. A formação profissional pautada tão somente na relação de cálculo entre os meios considerados mais eficazes para a formação profissional e pautada na primazia do econômico, (e não sustentada nos princípios ético-políticos que identificam uma sociedade democrática), torna-se um espaço fértil para a reprodução da ordem social moderna, dominada pela lógica do capitalismo. 
Importa considerar neste momento, mesmo que de maneira breve para os fins do presente trabalho, aspectos chave da análise que Max Weber elaborou sobre a condição universitária do seu tempo, que foram registrados no célebre texto "A ciência como vocação". Para ele, paradoxalmente, a universidade alemã no início do século XX, que deveria ser um espaço privilegiado do processo de compreensão racional da realidade, estava sendo dominada por professores que se aproximavam do demagogo e do "profeta", portanto, daquele que do alto da sua cátedra, e munido do seu carisma, professa "A Verdade", sempre calcada em juízos de valor sobre a realidade social que se querem incontestáveis. Atento ao risco desse processo (e mesmo se reconhecendo como um Quixote que luta contra moinhos de vento, sendo incapaz de vencê-los), o sociólogo alemão sentencia peremptoriamente:

Enquanto tentamos produzir intelectualmente novas religiões, chegaremos, em nosso âmago, na ausência de qualquer nova e autêntica profecia, a algo semelhante e que terá para nossa alma efeitos ainda mais desastrosos. As profecias que caem das cátedras universitárias não têm outro resultado senão o de dar lugar a seitas de fanáticos e nunca produzir comunidades verdadeiras. (WEBER, 2003b, p. 57-58)

Com esse diagnóstico que situa a universidade alemã como sendo uma instituição colonizada por novos profetas dotados do devido carisma, nos mostra um sombrio panorama com relação ao desenvolvimento da racionalidade na modernidade. Justamente no espaço em que o trabalho intelectual deveria servir à experiência da liberdade de pensamento e à formação de sujeitos livres, se observa, paradoxalmente, a forte presença da irracionalidade, que se apresenta na forma de "igrejas acadêmicas". Diagnóstico semelhante, porém com nuances próprias, também se observa na estratégia argumentativa de Pierre Bourdieu e Passeron, no que diz respeito ao papel desempenhado pelo professor universitário enquanto um profeta portador de carisma que confirma a ideologia do dom.

A seguir, faremos a análise da obra "Os Herdeiros" tendo como horizonte analítico os conceitos e princípios teórico-metodológicos acima delineados. Ainda, 
teremos como princípio norteador da análise o conceito de tipo-ideal de ação, em particular o de ação racional, com relação a fins e de ação racional, com relação a valores.

\section{O tipo ideal de ação racional com relação a fins n'Os herdeiros}

A obra em comento se constitui de três capítulos, a conclusão e dois apêndices nos quais se apresenta a base empírica utilizada como fundamento para a elaboração das análises do sistema de ensino superior francês. No primeiro capítulo, os autores se debruçam sobre os dados estatísticos que Ihes permitem sustentar a tese de que o sistema superior de ensino contribui para reproduzir as desigualdades sociais, de classe e sexo, e não para reduzi-las. No segundo capítulo se apresenta o jogo, com as suas respectivas regras, ao qual os estudantes universitários se entregam para poderem participar da vida universitária. No terceiro capítulo, os autores procuram desvendar os mecanismos de produção da relação mistificada dos estudantes com a atividade intelectual. Finalmente, nas conclusões, observamos a preocupação com apresentar um horizonte outro para que o sistema de ensino francês possa efetivamente operar no sentido da realização da promessa moderna de estar a serviço da promoção da igualdade social.

Interessa também neste momento chamar a atenção para a escolha do título da obra. Se pensarmos a partir da sociologia weberiana poderemos concluir que a escolha de "Os Herdeiros" como título, já contém a crítica que orientará todo o processo argumentativo, uma vez que remete à ideia da dominação tradicional calcada na reprodução das relações de poder a partir da herança dos membros de um segmento ou estamento social da sua condição social, pelo simples fato de terem nascido nesse contexto. Os "bem nascidos" bourdieusianos herdam da sua condição social uma bagagem cultural que os diferencia legitimamente dos outros, sendo mistificada a partir da ideologia do dom. Condição essa que será reforçada e reproduzida pelo sistema de ensino, em particular, neste caso, pelo sistema de ensino superior. Assim, na análise crítica realizada no livro, pode ser identificada a presença da inspiração weberiana já no 
título da obra, ao remeter à reprodução da dominação tradicional com a qual o sistema de ensino contribui, não realizando a promessa moderna de uma sociedade na qual a democratização da educação se constitui em princípio fundamental.

Os conceitos centrais de origem weberiana com os quais os autores operam no livro em análise são os de tipo ideal e tipo ideal de ação. A primeira referência ao conceito de tipo ideal se observa no capítulo 2, "Jogos sérios e jogos de seriedade", quando os autores fazem menção ao caráter ideal-típico da imagem do estudante (ao mesmo tempo caricata e realizada) como alguém que se entrega ao jogo intelectual marcado pelo diletantismo e pela adesão a ele com ares de atividade desinteressada. Embora reconhecendo que essa é uma marca distintiva do estudante de origem burguesa, os autores alertam para a possibilidade dela não se extinguir, mesmo que os estudantes oriundos das classes populares venham a se tornar majoritários na universidade. (BOURDIEU; PASSERON, 2014). Esse tipo ideal da conduta estudantil é considerado uma forma mistificada de relação com os estudos, cujas causas os autores procuram compreender, assim como também desconstruir.

Assim, para entrar no jogo intelectual presente no meio universitário, o estudante teria que assumir como própria uma identidade que represente uma aparente desconsideração pela relação entre o fim de se formar em uma determinada profissão, visando projetar seu futuro e a sua vida presente calcada na prática da atividade intelectual que deve ser experienciada como um fim em si mesmo. Ainda, esse modo de construção da imagem ideal-típica do estudante faculta os autores a situarem a conduta do estudante universitário sem estar relacionada a um dos tipos de ação definidas por Weber, pelo menos de maneira inicial. Contudo, essa elaboração servirá de baliza para a construção de um dos aspectos que interessa à elaboração da análise empreendida, qual seja a de identificar o caráter mistificado dos estudantes universitários com os estudos superiores.

Por outro lado, a estratégia que se observa no terceiro capítulo, “Aprendizes ou aprendizes de feiticeiros?", se orienta por contrastar essa construção ideal-típica com o que os autores entendem que seria ou deveria ser a construção ideal-típica com relação a 
fins de um estudante do ensino superior. Para tanto, Bourdieu e Passeron (2014) afirmam que:

\begin{abstract}
Para compreender em que e por que a situação do estudante encerra a possibilidade objetiva de uma relação irreal ou mistificada dos estudos e do futuro para os quais eles preparam, é preciso construir, ao menos para fins heurísticos, o tipo ideal da conduta estudantil perfeitamente conforme com a racionalidade, conduta que envolveria exclusivamente meios concebidos como adequados em relação a fins postos de maneira unívoca. (p. 76)
\end{abstract}

Nesse momento, os autores passam a situar o tipo ideal da conduta estudantil pautada no tipo de ação racional com relação a fins, que logo a seguir é definida como uma baliza normativa, contribuindo com a compreensão da maneira e dos motivos a partir dos quais a relação dos estudantes com os estudos adquire um caráter mistificado.

\begin{abstract}
Ainda que se compreenda melhor o sentido das condutas reais confrontando-as com a conduta ideal-tipicamente racional, dotada de evidência própria a toda conduta racional dos estudos permite avaliar a distância que separa da conduta racional as condutas reais das diferentes categorias de estudantes e, mais precisamente, comparar essas condutas não a uma norma arbitrariamente escolhida, mas ao modelo construído do que seria a conduta estudantil se estivesse perfeitamente conforme com o que ela pretende ser em algumas das suas expressões ideológicas, isto é, perfeitamente racional em relação aos fins que coloca para sua própria existência. Se advier que o modelo da conduta construído na hipótese da conformidade com os fins racionais que estão objetivamente inscritos na situação de estudante parece utopia quando comparado às condutas reais dos estudantes, e faz parecerem utópicas as ideologias milenaristas de alguns grupos de estudantes, é porque ele teria preenchido sua função de pedra de toque da racionalidade e do realismo das condutas e das ideologias. (Ibid. p. 76)
\end{abstract}

O que nos interessa sublinhar é que o modus operandi com o qual os autores se apropriam do conceito de tipo ideal parece assumir uma função estratégica, qual seja, o de apresentar o caráter irrealizado do projeto moderno, assentado no esclarecimento que a razão possibilita, e, no mesmo movimento, denunciar a forma tradicional e 
carismática com a qual operam as instituições universitárias francesas que se querem modernas.

Assim, os sociólogos franceses apresentam o perfil ideal-típico da conduta de um estudante universitário se fosse orientada pela ação racional conforme fins. Para eles:

Decorre daí (do fato da condição de estudante pressupor a sua negação) que uma condição que se define como provisória e transitória somente pode ter sua seriedade na condição profissional para a qual prepara, ou, em outros termos, que o presente somente tem realidade aqui por procuração ou antecipação. Também, com a condição de chegar até o fim da lógica, a maneira mais racional de exercer o métier de estudante consistiria em organizar toda a ação presente em relação às exigências da vida profissional e em pôr em prática todos os meios racionais para atingir, no menor tempo possível, e o mais perfeitamente possível, esse fim explicitamente assumido. (p. 78)

Vemos na passagem acima que, de forma contrária à forma mistificada, a relação que deveria adquirir o estudante, enquanto profissional em formação com a atividade intelectual, seria a de um sujeito que se prepara para o futuro, e que vive o presente, de maneira vinculada ao seu futuro profissional. A relação com o presente adquiriria a forma de uma antecipação do futuro a ser vivido, bem como pressuporia a tentativa de acelerar o quanto for possível a formação superior. Nesse movimento, vemos que a estratégia dos autores na construção da ação racional com relação a fins adquire o caráter de baliza normativa, sobre um suposto dever ser da relação dos estudantes do ensino superior com os estudos. Assim fazendo, esse movimento permite sustentar a denúncia do caráter mistificado dos estudantes com a atividade intelectual.

Além disso, outro aspecto a ser destacado é que essa forma de relação com os estudos se apresenta como um elemento inerente à identidade de todo e qualquer estudante, se revela, na realidade, como uma característica dos estudantes de origem burguesa, que não se encontram condicionados às urgências econômicas com as quais se confrontam os estudantes das classes populares. Nas palavras dos autores: 
A relação que os estudantes mantêm com seu futuro, isto é, com seus estudos, tem a ver diretamente com as chances objetivas que os indivíduos de sua classe têm de acesso ao ensino superior, os estudantes das classes altas podem se contentar com projetos vagos, pois nunca tiveram que escolher verdadeiramente fazer o que fazem, coisa banal em seu meio e mesmo em sua família, enquanto os estudantes das classes baixas não podem deixar de se interrogar sobre o que fazem porque têm menos chances de esquecer que poderiam não fazê-lo. (p. 85)

Merece também atenção na análise do sistema francês de ensino superior, o papel ocupado pelos professores. Nesse caso, a crítica recai sobre o lugar que os docentes universitários assumem como portadores do carisma, confirmando o próprio dom, e operando no sentido de criar uma relação circular de reciprocidade e reconhecimento entre os eleitos. Assim fazendo, a legitimação do dom, implica, paralelamente, justificação mistificada da exclusão dos não eleitos. Também essa maneira de operar sinaliza que o sistema francês de ensino superior ainda se encontra preso na lógica da dominação tradicional, não tendo alcançado o lugar que lhe cabe enquanto espaço de formação de profissionais, de especialistas. Lemos na obra em análise:

A experiência mistificada da condição estudantil autoriza a experiência encantada da função professoral: ao estabelecimento da relação, tecnicamente organizada, entre um pedagogo e um aprendiz pode substituir-se o encontro de eleição entre eleitos. Porque permite aos professores se apresentarem como mestres que comunicam por dom pessoal uma cultura total, esse jogo das complacências recíprocas e complementares obedece à lógica de um sistema que, como o sistema francês em sua forma presente, parece servir a fins tradicionais mais que racionais e trabalhar objetivamente para formar homens cultos mais que homens de métier. O próprio curso magistral ainda é uma troca porque a proeza da virtude se volta implicitamente para sujeitos dignos de recebê-la e de apreciá-la. A troca universitária é uma troca de dons na qual cada um dos parceiros concede ao outro o que espera dele, 0 reconhecimento do seu próprio dom. (p. 80 - o negrito é nosso)

Vale apontar, no trecho acima, que a denúncia dos autores procura demonstrar de que maneira o sistema de ensino, por não operar efetivamente de forma racional, mas antes seguindo a lógica da ação tradicional, contribui para a reprodução de uma forma de 
dominação que deveria ter sido superada na modernidade. Dessa maneira, os autores objetivam evidenciar que o papel a ser cumprido pelo sistema de ensino no desenvolvimento do projeto moderno, está longe de ser uma realidade. Dito de outro modo, a luz da racionalização dos processos ainda é um projeto a ser realizado no âmbito do ensino superior francês.

Além disso, o caráter de sujeitos portadores de carisma assumido pelos professores leva a que a relação dos estudantes com os estudos também seja pautada pelo recurso a estratégias com conotações mágico-religiosas, e não em uma relação racional com a atividade intelectual. Ainda, essa forma de relação seria uma forma de complacência dos alunos para com os professores, evitando, assim, a incorporação de técnicas racionais e da disciplina que seriam inerentes às exigências da formação superior. Segundo Bourdieu e Passeron

(...) os mestres carismáticos somente reforçam nos estudantes o sentimento de impotência, de arbitrariedade ou de predestinação ao fracasso. De sua parte, porque lhes agrada mais e custa-lhes menos acreditar no carisma do que controlar laboriosamente técnicas, os estudantes condenam-se a uma imagem do sucesso escolar na qual, na ausência de dom, somente a magia pode agir. (p. 86)

Esse modo de operar com a figura do professor se aproxima, embora de maneira singular, da denúncia de Weber sobre o caráter assumido pelo professor que evoca o papel de profeta. Aqui, o que se observa é a crítica ao professor como aquele não que ocupa o lugar de guia político, mas daquele que justifica a condição de eleitos dos portadores do "dom”, ocultando, dessa maneira, a diferença na relação com os estudos pautada pelo pertencimento a diferentes classes sociais. O professor é aquele que justifica o próprio dom e o dos eleitos.

A aposta dos autores no projeto de uma pedagogia racional, que é apresentada no final do terceiro capítulo, e desenvolvida na conclusão, confirma a crença de Bourdieu e Passeron na positividade da ação racional com relação a fins, desde que subordinada à ação racional com relação a valores. Para eles a pedagogia racional, que deveria se valer 
da análise sociológica das desigualdades sociais e da sua implicação na relação dos estudantes com a cultura, traria uma contribuição decisiva para o desmascaramento da ideologia do dom e para a realização do ideal moderno da construção de um sistema de ensino que estivesse a serviço da igualdade social. Lemos na obra:

Uma pedagogia realmente racional deveria fundamentar-se na análise dos custos relativos das diferentes formas de ensino (cursos, trabalhos prático, seminários, grupos de trabalho) e dos de ensino (desde o simples conselho técnico até a direção efetiva dos trabalhos de estudantes); ela deveria levar em conta o conteúdo do ensino ou os fins profissionais da formação e, visando aos diversos tipos de relações pedagógicas, não deveria esquecer seu rendimento diferencial segundo a origem social dos estudantes. Em qualquer hipótese, ela está subordinada ao conhecimento que se terá da desigualdade cultural socialmente condicionada e à decisão de reduzi-la. (Ibid., p. 99)

A partir desse posicionamento, os autores procuram conciliar a defesa de uma pedagogia racional, com o projeto de democratização da educação enquanto promessa moderna. Eles consideram que a pedagogia racional deve estar situada no contexto do projeto moderno de educação que assume como fim último colocar o sistema de ensino a serviço da promoção da igualdade social. Dessa maneira, a estratégia argumentativa do trabalho está balizada pela subordinação da ação racional com relação a fins - da pedagogia racional -, aos valores, assumidos como cláusulas pétreas, que deveriam ser subjacentes a uma sociedade que se queira democrática, e que postulam, no que diz respeito à transmissão institucionalizada da cultura, que a todos os sujeitos deveria ser possibilitado o acesso aos bens culturais e às aptidões que, em particular para os sujeitos oriundos das classes desfavorecidas, somente a instituição escolar poderia permitir seu acesso. Vale resgatar as palavras presentes no final do texto:

Se se concorda que o ensino realmente democrático é aquele que se atribui como fim incondicional permitir ao maior número possível de indivíduos apreender no menor tempo possível, o maior número possível de aptidões que caracterizam a cultura escolar em um dado momento, vê-se que ele se opõe tanto ao ensino tradicional voltado à formação e à seleção de uma elite de pessoas bem-nascidas quanto ao ensino 
tecnocrático voltado à produção em série de especialistas sob medida. (Ibid., p. 101 - itálico no original)

O projeto de uma pedagogia racional coincide com o projeto político ainda não realizado de uma sociedade que orienta sua ação pela ação racional com relação a valores e a fins (nessa ordem), e que, assim fazendo, teria como mandamento a diminuição das desigualdades, pelo menos no que diz respeito ao acesso igualitário à cultura. Essa configuração do sistema de ensino levaria a superar a dominação tradicional que reina nessa instituição e que promove a reprodução das desigualdades sociais por "favorecer os favorecidos" ou os "bem nascidos", bem como a se contrapor ao avassalador processo de pautar o sistema de ensino tão somente por critérios técnicos, mormente de origem econômica, orientados à formação de especialistas, sem qualquer consideração por um projeto de sociedade democrática. Diagnóstico que guarda, em tempos contemporâneos, uma surpreendente validade.

\section{Considerações finais}

Neste breve ensaio, pudemos resgatar alguns elementos que consideramos relevantes para a compreensão da estratégia argumentativa presente n'Os Herdeiros. Em particular, vemos que a forma de apropriação de conceitos e do método weberianos se torna tanto um marco analítico para a compreensão e a crítica do sistema de ensino superior francês, quanto uma forma de afirmar um posicionamento político em favor de um projeto moderno não realizado. Nesse momento, ainda vemos no horizonte a crença de que o sistema de ensino francês poderia operar num sentido diferente, isto é, como um espaço importante para contribuir com a diminuição das desigualdades sociais.

Neste nosso tempo em que a descrença na razão avança de maneira crescente, e nos quais a razão é colocada no banco dos réus e tornada, não raro, o bode expiatório para a justificação e a decretação do fracasso do projeto moderno, uma obra dessa natureza - de cuja aparição já estamos a cinquenta anos de distância - nos chama a 
atenção para a importância de não eliminarmos a aposta em uma sociedade que possa ser efetivamente mais democrática, se orientada pela racionalidade. O que não retira de forma alguma (pelo contrário aumenta) a necessidade de discutirmos o próprio conceito de racionalidade com o qual operamos. Ainda, "Os Herdeiros" nos instiga a pensarmos a necessidade de subordinarmos a ação racional com relação a fins aos valores inerentes a uma sociedade democrática na construção do sistema de ensino. No aparente anacronismo dessa obra reside, certamente, sua atualidade.

\section{Referências}

BOURDIEU, Pierre; PASSERON, Jean-Claude. Os Herdeiros - os estudantes e a cultura. Florianópolis: Ed. da UFSC, 2014.

WEBER, Max. Economia e sociedade: fundamentos da sociologia compreensiva. Brasília: Ed. da UnB. São Paulo: Imprensa Oficial do Estado de São Paulo, 1999.

WEBER, Max. Ensaios de sociologia. 5a. Ed. Rio de Janeiro: Guanabara Koogan, 1982.

WEBER, Max. Ensaios sobre a teoria das ciências sociais. São Paulo: Centauro, $2003 a$.

WEBER, Max. Ciência e política - duas vocações. São Paulo: Martin Claret, 2003b.

WEBER, Max. A ética protestante e o "espírito" do capitalismo. São Paulo: Companhia das Letras, 2004.

Recebido em: 16/10/2013 Aprovado em: 14/02/2014

Universidade do Estado de Santa Catarina - UDESC Programa de Pós-Graduação em Educação - PPGE Revista Linhas Volume 15 - Número 29 - Ano 2014 revistalinhas@gmail.com 